\title{
Evaluation of bread wheat for both seedling and adult plant resistance to stem rust
}

\author{
Nzuve F. M. ${ }^{1 \star}$, Bhavani S. $^{2}$, Tusiime G. ${ }^{1}$, Njau P. ${ }^{3}$ and Wanyera ${ }^{3}$ \\ ${ }^{1}$ Makerere University, P O Box 7062, Kampala, Uganda. \\ ${ }^{2}$ CIMMYT, Kenya, P O Box, 1041, Nairobi, Kenya. \\ ${ }^{3}$ Kenya Agricultural Research Institute, P O Box Private Bag, Njoro, 20107, Kenya.
}

Accepted 13 September, 2012

\begin{abstract}
Wheat is an important staple food crop in sub-Saharan Africa. However, the current wheat consumption of 900000 tons in Kenya outweighs the wheat production of 350000 tons given the high population growth and inflation. The stem rust currently poses the greatest threat to wheat production due to the emergence of the virulent race of the Puccinia graminis f. sp tritici, Ug99 (TTKS) and its variants Ug99 + Sr24 (TTKSK) and Ug99 + Sr36 (TTKST) leading to about 70 to $100 \%$ yield losses. This study aimed at evaluating twenty-five wheat genotypes for both field and seedling resistance to stem rust. The genotypes were grown in an alpha lattice design and in two replicates both in the greenhouse and in the field at Kenya Agricultural Research Institute (KARI), Njoro. The seedling stage infection types were scored based on Stakman et al. (1962) scale. At the adult plant stages, the stem rust disease severity was based on modified Cobb's scale. The genotypes showed diverse seedling and adult plant resistance responses. The most resistant entries, KSL-2, KSL-3 and KSL-20 also exhibited the pseudo black chaff (PBC) trait implying they contain the Sr2 gene in their background; the basis of breeding for durable resistance to stem rust in wheat. These lines with high stem rust resistance could be backcrossed to the adapted and high yielding but susceptible Kenyan wheat varieties to avert further wheat yield declines.
\end{abstract}

Key words: Stem rust, wheat, Ug99, resistance, disease severity.

\section{INTRODUCTION}

Globally wheat is grown on 225 million ha with a total production of 600000 tons (Singh et al., 2008). In Kenya, the wheat production of 350000 tons does not match the current consumption of 900000 tons. The favourable warm climatic conditions in East African region have sustained increased fungal populations leading to high epidemics of stem rust or black rust. Stem rust (caused by Puccinia graminis f. sp tritici Erik and E. Henns) is windborne and capable of infecting vast lands. The fungus $P$. graminis $\mathrm{f}$. $\mathrm{sp}$ tritici is the most damaging because it is an obligate biotroph with five spore stages

*Corresponding author. E-mail: fmbute@yahoo.com or felistermusembi@gmail.com. Tel: +254723048386. and has a heterothallic mating design (Beteselassie et al., 2007). Stem rust is also considered as the greatest threat to wheat production in the East African region due to the emergence of a virulent race of the $P$. graminis $f$. sp tritici, Ug99 (TTKS). In 1998, wheat varieties carrying the Sr31 gene widely grown in Uganda in 1998 were observed to exhibit high susceptibility to stem rust and a race Ug99 was associated with this virulence. This race was later designated TTKS based on North American stem rust nomenclature (Xu et al., 2009). The Ug99 has continued to evolve into more virulent forms like Ug99 + Sr24 (TTKSK) and Ug99 + Sr36 (TTKST) showing virulence to stem rust resistant genes Sr24 and Sr36, respectively (Singh et al., 2008). The Ug99 spores have been spread over vast areas causing epidemics and high yield losses in Kenya and Ethiopia in 2002, Sudan, Iran 
and Yemen in 2007 with the possible route of stem rust spread been proposed as East Africa - Middle East West Asia - South Asia (Ayliffe et al., 2008; Singh et al., 2008).

Previously, resistant varieties have been rendered susceptible due to their narrow genetic base (Beteselassie et al., 2007). Additionally, the current wheat monoculture among the East African farmers has offered a green bridge for the rust spores leading to the increased $P$. graminis f. sp tritici distribution and frequency (Saari and Prescott, 1985). The problem is further aggravated by the ability of the stem rust fungus to infect the wheat leaves, stems, heads and sheaths reducing a healthy wheat field to black stubble of shriveled kernels predisposing crops to extensive lodging and even total crop loss (Vidal, 2009; Wanyera et al., 2004). About $90 \%$ of the world's wheat is grown in the Ug99 spore path (Ayliffe et al., 2008) and is threatened by the Ug99. With the current economic constraints, ineffective crop husbandry practices, inflation and high population growth, use of chemicals is economically and environmentally unviable. Thus, host resistance breeding remains the only feasible option.

Among the 45 stem rust resistance genes catalogued (Singh et al., 2008); only Sr2 gene is adult plant resistance gene, while the rest are race specific. The race specific stem rust resistance genes are expressed at both seedling and adult plant stages. These genes show resistance to some stem rust races but are susceptible to others. Through mutations, climatic changes (Semenov and Halford, 2009), sexual and para sexual recombinations (Singh et al., 2008; Burdon, 1993) and migration of the virulent forms into new regions; continuous breakdown of the $P$. graminis $\mathrm{f}$. $\mathrm{sp}$ tritici into more virulent forms (Synman et al., 2004) has led to the boom and bust cycles (Qamar, 2006).

On the other hand, the non-race specific genes which show resistance to all known pathotypes (Tabassum, 2011) are very important genes with respect to combating the threat posed by the TTKS and its variants TTKSK and TTKST. The non-race specific genes appear susceptible at seedling stage but exhibits moderately to highly resistant responses at adult plant stages; for example, the presence of Sr2 gene in many wheat genotypes appears as the pseudo black chaff (PBC) phenotype and is a slow rusting gene. When the non-race specific genes are combined with 4 to 5 genes of minor or additive effect, a near immunity could be achieved (Singh et al., 2008). The use of non-race specific genes is being emphasized and it has formed the basis of durable resistance in wheat breeding programs.

The replacement of currently susceptible wheat varieties with more stem rust resistant varieties remains a high priority given the favourable climatic conditions in East African region for the infection and spread of stem rust (Ug99 and its variants). Urgent interventions in identifying good sources of resistance to stem rust will offer an indispensable relief and this formed the thrust of this study.

\section{MATERIALS AND METHODS}

\section{Host material}

Twenty-five wheat lines were selected from the international wheat screening nursery in 2008 (designated as 'Kenya selections 2008 or KSL)' at Kenya Agricultural Research Institute (KARI), Njoro. These wheat lines showed high resistance to stem rust during the main season screening experiments in 2008 and were also elite in terms of plant height and earliness. They were then planted during the 2009 and 2010 growing seasons at KARI, Njoro. This site lies at $0^{\circ} 20^{\prime} \mathrm{S}$; $35^{\circ} 56^{\prime} \mathrm{E}$, and $2185 \mathrm{~m}$ above sea level (Ooro et al., 2009). The minimum and maximum temperatures of 9.7 and $23.5^{\circ} \mathrm{C}$, respectively and mean rainfall of $900 \mathrm{~mm}$ favour infection and spread of the $P$. graminis races. This site is used for large-scale wheat screening for resistance to stem rust in wheat (Jin et al., 2007). A susceptible line designated as "CACUKE" was used as a check in these experiments.

\section{Field experiments}

The twenty-five wheat lines and the check "CACUKE" were grown during the 2009-off season and 2010- main season. Fifty gram of each entry were grown as two $1 \mathrm{~m}$ row plots spaced at $30 \mathrm{~cm}$ in an alpha lattice design in two replicates. A mixture of seven spreaders or infector rows were planted perpendicular to all the plots and in the border of the experimental plots (Jin et al., 2007). They were later inoculated with stem rust spores when the plants were at almost booting stages by use of a syringe in the evenings to create an artificial disease epidemic and ensure uniform inoculum dissemination. When there was no rainfall, the plants were repeatedly irrigated to enhance stem rust infection and spread. The stem rust severity scoring began when the spreader rows attained about 30 to $50 \%$ susceptible responses based on modified Cobbs' scale where $0 \%=$ immune and $100 \%=$ completely susceptible (Peterson et al., 1948). The note taking was repeated weekly until the plants attained physiological maturity. The infection responses or reactions (plant response to stem rust infection in the field among the adult plants) were noted based on Roelfs et al. (1992) scale (Table 1). The other agronomic data collected included days to heading, yellow rust disease severity (based on modified Cobb's scale), PBC (as an indicator of the presence of Sr2 adult plant rust resistance gene), percentage stem lodging, plant height and thousand kernel weight (TKW). The days to $50 \%$ flowering were recorded when $50 \%$ of spikes completely emerged from the boot as an indicator of maturity. Plant height was measured as the distance in centimetres from soil level to the tip of the spikes of randomly selected four plants per plot. A thousand seeds from each plot were weighed and weights recorded in grams to note the TKW.

\section{Greenhouse experiments}

The same twenty-five lines and the check "CACUKE" were grown in pots and placed in the growth chamber of the greenhouse. When the plants had fully expanded primary leaves, they were inoculated with stem rust spores collected from infected stems of Sr24 gene containing wheat lines in the inoculation chamber. The infected stems were chopped into small pieces and put in a beaker 
Table 1. Infection types and field infection responses showing the symptoms.

\begin{tabular}{cll}
\hline *Infection type & Symptoms & \#Infection responses / reactions \\
\hline 0 & No uredinia or other macroscopic sign of infection & Immune \\
$0 ;$ & Few faint flecks & Resistant (R) \\
$;$ & No uredinia but hypersensitive necrotic or chlorotic flecks are present & Resistant (R) \\
1 & Small uredinia often surrounded by a necrosis & Resistant to moderately resistant (RMR) \\
2 & Small to medium uredinia often surrounded by chlorosis & Resistant to moderately resistant (RMR) \\
3 & Medium sized uredinia without chlorosis or necrosis & Moderately susceptible (MS) \\
4 & Large uredinia without chlorosis or necrosis & Susceptible (S) \\
\hline
\end{tabular}

*Infection types based on Stakman et al. (1962) scale for seedling resistance; \#Field infection responses based on Roelfs et al. (1992) scale for adult plant resistance.

Table 2. Analyses of variances for the various traits of importance among the wheat lines.

\begin{tabular}{lcccc}
\hline Source of variation & Plant height & Stem rust & Yellow rust & Days to $50 \%$ flowering \\
\hline Genotypes & $166.74^{\star *}$ & $557.37^{\star *}$ & $328.43^{\star *}$ & $122.261^{* *}$ \\
Season & $12168.85^{\star *}$ & 25 & $3831.61^{* *}$ & $3147.21^{* *}$ \\
Genotypes season & 37.05 & $70.31^{*}$ & $244.11^{\star *}$ & $19.731^{*}$ \\
Residual & 29.98 & 28.96 & 56.75 & 9.727 \\
Total & & & & \\
\hline
\end{tabular}

** and *, Significantly different at 0.01 and 0.05 , respectively.

containing Soltrol, a light mineral oil and then shaken (Jin et al., 2007). The solution was then sieved using a cheese cloth to obtain the spore solution (inoculum). The inoculum was then sprayed onto the plants from a distance and allowed to dry for about 20 min. The inoculated plants were incubated under polythene hoods in natural light at 18 to $20^{\circ} \mathrm{C}$ for $48 \mathrm{~h}$ after which they were moved to temperature and irrigation-controlled greenhouse rooms for disease scoring after 13 to 14 days post inoculation. The Infection types which connoted the expression of host-pathogen interaction was made based on 0 to 4 infection type of Stakman et al. (1962) scale as shown in Table 1.

\section{Data analysis}

The analysis of variance was done to determine the significance of the differences among the wheat lines (genotypes) for the different agronomic traits. The wheat genotypes were considered as fixed, whereas seasons were random effects. The least significant differences $(P=0.05)$ was used to compare the genotypic means. A Pearson correlation coefficient was done to establish the relationship between the different traits measured.

\section{RESULTS}

KARI, Njoro is situated in the Rift valley province of Kenya with variable climatic conditions. Throughout the years of testing, heavy rains and high temperatures experienced offered favourable conditions providing a green bridge for infection and spread of the $P$. graminis $f$. $\mathrm{sp}$ tritici. Significant variations were noted for stem rust, plant height, yellow rust and days to $50 \%$ flowering among the wheat genotypes tested across the seasons (Table 2).

\section{Field tests for adult plant resistance}

There was variation in the stem rust severities in the field ranging from 1 to $90 \%$ based on the modified Cobb's scale (Table 3). A diverse field reaction ranging from trace resistance (TR) to moderately susceptible (MS) to susceptible (S) responses was observed. Trace responses were displayed as very small chlorotic flecks coupled with no visible pustules on the wheat stems or stalks. In the field, fourteen of the twenty-five wheat lines tested displayed resistant to moderately resistant (RMR) to moderately resistant (MR) responses and disease severities of up to $30 \%$. These lines were characterized by small to medium sized pustules showing chlorosis and a rough texture on the stems. On the other hand, the check "CACUKE" displayed highest disease severity of $90 \%$ and completely susceptible (S) responses.

Considering other traits of economic importance in breeding for disease resistance in wheat, the check, "CACUKE" showed the highest yellow rust resistance despite the high stem rust susceptibility. The genotype KSL-19 which displayed trace responses (TR) to stem rust also displayed high resistance to yellow rust. Further on, KSL-5 and KSL-19 also displayed good earliness and 
Table 3. Performance of wheat lines tested for resistance to stem rust and other traits at the adult plant stages.

\begin{tabular}{|c|c|c|c|c|c|c|c|c|c|c|c|}
\hline \multirow{2}{*}{ Genotype } & \multirow{2}{*}{ Parentage } & \multirow{2}{*}{$\begin{array}{l}\text { Maturity } \\
\text { (days) }\end{array}$} & \multirow{2}{*}{$\begin{array}{l}\text { Plant height } \\
\text { (cm) }\end{array}$} & \multicolumn{2}{|c|}{ Stem rust } & \multicolumn{2}{|c|}{ Yellow rust } & \multirow{2}{*}{ bPBC } & \multirow{2}{*}{$\begin{array}{l}{ }^{\text {cTKW }} \\
\text { (g) }\end{array}$} & \multicolumn{2}{|c|}{$\begin{array}{l}\text { dInfection } \\
\text { types }\end{array}$} \\
\hline & & & & $\begin{array}{c}\text { Severity } \\
(0-100)\end{array}$ & aFR & $\begin{array}{l}\text { Severity } \\
(0-100)\end{array}$ & aFR & & & 2010 & 2012 \\
\hline KSL-1 & COHUEL/SBE-0050(ARGETINA-MIRANDA) & 86.5 & 66.31 & 1 & TR & 16.5 & MS & + & 20.5 & 0 & 0 \\
\hline KSL-2 & CWANA 1st SR RESIS. ON - ETH - OS71 & 91.5 & 89.59 & 8.75 & RMR & 7.5 & MR & + & 19.8 & 1 & 1 \\
\hline KSL-3 & MON'S'/ALD'S'//TOWPE'S' & 92.5 & 88.31 & 8.75 & RMR & 8.75 & MR & + & 22.8 & 0 & ; \\
\hline KSL-4 & HRZ05.0078 & 86.25 & 78.94 & 8.75 & RMR & 7.5 & $\mathrm{M}$ & - & 27.3 & ;1- & 0 \\
\hline KSL-5 & $\begin{array}{l}\text { THELIN\#2/ TUKURU CGSS02Y00118S-099M-099Y- } \\
\text { 099M-16Y-OB }\end{array}$ & 71.75 & 72 & 16.25 & MR & 8.75 & MR & - & 28.6 & 0 & ; \\
\hline KSL-6 & IGW3207 & 77.75 & 81.12 & 45 & MS & 11.25 & MR & - & 27.6 & $0 ; 1 \mathrm{p} 2$ & ; \\
\hline KSL-7 & $\begin{array}{l}\text { SERI.1B*2/3/KAUZ*2/BOW//KAUZ/4/PBW343*2/TUKUR } \\
\text { U/5/C80.1/3*BATAVIA//2*WBLL1 }\end{array}$ & 87.5 & 67.06 & 1 & TR & 18.75 & MR & - & 25.7 & 0 & ; \\
\hline KSL-8 & WHEAR/VIVITSI/WHEAR & 81.25 & 81.69 & 32.5 & $\mathrm{M}$ & 18.75 & M & - & 27.5 & $1-$ & 0 \\
\hline KSL-9 & WHEAR/SOKOLL & 73.25 & 83.56 & 23.75 & MR & 10 & M & + & 26.7 & ;1- & 2 \\
\hline KSL-10 & WHEAR/JARU//WHEAR & 80.25 & 79.5 & 23.75 & M & 30 & $S$ & - & 30.9 & $1-$ & ; \\
\hline KSL-11 & WHEAR/VIVITSI/3/C80.1/3*BATAVIA/2WBLL1 & 81.75 & 75.25 & 28.75 & MR & 32.5 & MSS & - & 25 & $1-$ & 0 \\
\hline KSL-12 & PBW343*2/KUKUNA//PBW343*2/KUKUNA/3/PBW343 & 86.5 & 78.38 & 25 & M & 21.25 & M & - & 25.7 & $1-$ & 0 \\
\hline KSL-13 & SUPER SERI\#1 & 83.25 & 86.88 & 23.75 & MR & 22.5 & M & + & 28.8 & $1+$ & ; 1 \\
\hline KSL-14 & WHEAR/VIVITSI//WHEAR & 82.25 & 86 & 18.75 & RMR & 36.25 & MSS & - & 23.6 & $;+$ & 0 \\
\hline KSL-15 & WHEAR/KUKUNA/WHEAR & 82.5 & 88.12 & 18.75 & RMR & 37.5 & MSS & - & 33.8 & $1=$ & ; \\
\hline KSL-16 & WHEAR/VIVITSI/3/C80.1/3*BATAVIA/2*WBLL1 & 74.5 & 81.47 & 35 & M & 21.25 & M & + & 23.9 & 0 & 0 \\
\hline KSL-17 & WHEAR/VIVITSI/3/C80.1/3*BATAVIA//2*WBLL1 & 83.25 & 85.75 & 25 & RMR & 18.75 & M & - & 28.7 & ;1- & ; \\
\hline KSL-18 & WHEAR/VIVITSI/3/C80.1/3*BATAVIA//2*WBLL1 & 83 & 81.06 & 32.5 & M & 15 & M & - & 24.6 & 1 & ; \\
\hline KSL-19 & SUNCO//TNMU/TUI & 72 & 74 & 1 & TR & 7.5 & M & - & 28.4 & 0 & 1 \\
\hline KSL-20 & $\begin{array}{l}\text { CHEN/AEGILOPS SQUARROSA } \\
\text { (TAUS)//BCN/3/VEE\#7/BOW/4/PASTOR/5/VERDIN } \\
\text { CMSS02M00361S-030M-15Y-0M-040Y-6ZTB-0Y-03B-0Y }\end{array}$ & 85 & 76.94 & 17.5 & RMR & 26.25 & MS & + & 36.5 & 0 & 0 \\
\hline KSL-21 & R07 F4-21258 & 86.5 & 69.5 & 1 & TR & 23.75 & MR & - & 32 & 0 & 0 \\
\hline KSL-22 & WHEAR/VIVITSI/3/C80.1/3*BATAVIA//2*WBLL1 & 83.25 & 81.09 & 23.75 & M & 17.5 & $\mathrm{M}$ & - & 28.9 & ;1- & ; \\
\hline
\end{tabular}


Table 3. Continued.

\begin{tabular}{|c|c|c|c|c|c|c|c|c|c|c|c|}
\hline KSL-23 & WHEAR/VIVITSI/3/C80.1/3*BATAVIA//2*WBLL1 & 83.5 & 82.38 & 31.25 & MR & 28.75 & MSS & - & 24.5 & $1-$ & ; \\
\hline KSL-24 & $\begin{array}{l}\text { CHEN/AEGILOPS SQUARROSA } \\
\text { (TAUS)//BCN/3/NEE\#7/BOW/4/PASTOR/5/VERDI } \\
\text { N CMSS02M00361S-030M-16Y-0M-040Y-16ZTB- } \\
\text { OY-03B-0Y }\end{array}$ & 79.5 & 79.56 & 16.25 & MR & 17.5 & MS & - & 28.7 & ;+ & 0 \\
\hline KSL-25 & (Yield trial 2007) & 89 & 85.38 & 23.75 & MR & 11.25 & MR & - & 30.7 & $1+$ & ;22+ \\
\hline \multirow[t]{2}{*}{ CACUKE } & CANADIAN/CUNNINGHAM//KENNEDY & 75 & 80 & 90 & $S$ & 5 & MR & - & 15 & $33+$ & $33+$ \\
\hline & Least significant differences & 6.267 & 11.003 & 10.814 & & 15.139 & & & 3.02 & & \\
\hline
\end{tabular}

${ }^{\mathrm{a}} \mathrm{FR}$, Field responses based on Roelfs et al. (1992); TR, trace responses; R, resistant; presence of hypersensitive necrotic or chlorotic flecks but no uredinia. MR, moderately resistant; small pustules surrounded by necrotic areas. (MRMS $=\mathrm{M}$ ). MS, moderately susceptible; medium sized pustules, no visible necros is but there is chlorosis. MSS, moderately susceptible to susceptible; medium to large sized pustules without chlorosis or necrosis. S, susceptible; large pustules, no necrosis or chlor osis. ${ }^{b}$ PBC, Pseudo black chaff where + and - implies presence and absence of the PBC trait respectively. ${ }^{\circ} \mathrm{TKW}$, thousand kernel weight where a thousand seeds from each plot were weighed and weights recorded in grams. ${ }^{\mathrm{d}}$ Infection types based on Stakman et al. (1962); 0, 1, 2 are resistant infection types while 33+ are susceptible infection types.

short plant height traits. In the field, KSL-5 was also characterized by some plants appearing as double dwarf (DD) in the 3 years of testing. The lines KSL-20 and "CACUKE" showed highest and lowest TKWs, respectively. The most susceptible line "CACUKE" had very shriveled grains in the field and in some plants there were no grains at all implying that stem rust negatively affected the grain quantity and quality (Table 3 ). A trait of great importance noted among seven of the wheat lines was the PBC trait suggesting these lines contain the Sr2 gene in their backgrounds and these genotypes could be integrated in breeding for durable resistance to stem rust in wheat (Table 3).

\section{Greenhouse test for seedling resistance}

There was successful inoculation as shown by the susceptible infection types of the check "CACUKE" of 33+ (Table 3). All the wheat lines tested for seedling resistance showed resistant infection types implying presence of seedling resistance.

\section{Correlation analysis among stem rust and the traits of importance}

The Pearson correlation coefficient analysis showed that days to $50 \%$ flowering were negatively correlated with stem rust severity and plant height. The TKWs displayed significantly different positive correlation with days to $50 \%$ flowering and plant height (Table 4).

The yellow rust trait showed a negative correlation with the stem rust and days to $50 \%$ flowering.

\section{DISCUSSION}

Despite the heavy stem rust disease pressure in the field during the years 2008, 2009 and 2010, some lines remained resistant. Among these wheat lines, four of the genotypes which showed trace infection responses also displayed resistant infection types at seedling stages. The trace reaction noted could be associated with hypersensitivity whereby fungal infection signals a defense mechanism leading to cell collapse which restricts further disease spread (Rubiales and Nicks, 2000). An appropriate crop improvement strategy like the use of inter specific and remote crosses or even the direct transfer of these resistance through backcrosses could be adopted to improve the adapted but highly susceptible wheat varieties being grown widely in Kenya
(Bartos
et
al.,
2002). 
Table 4. Pearson's correlation coefficients among the different agronomic traits.

\begin{tabular}{lccccc}
\hline Variable & Days to $\mathbf{5 0 \%}$ flowering & Plant height & Stem rust & TKW & Yellow rust \\
\hline Days to $50 \%$ flowering & - & & & & \\
Plant height & $-0.48^{* *}$ & - & & & \\
Stem rust & -0.02 & 0.23 & - & & \\
TKW & $0.67^{* *}$ & $0.64^{* *}$ & -0.17 & - & \\
Yellow rust & 0.11 & 0.09 & -0.09 & 0.31 & - \\
\hline
\end{tabular}

** and *, Significantly different at 0.01 and 0.05 , respectively.

The genotypes which displayed resistant to moderately resistant responses are of great importance to achieving effective breeding for durable resistance to stem rust. Nevertheless, MR to MS, and MS wheat lines showed statistically low stem rust disease severities despite the compatible host-pathogen reaction. In spite of the resistant infection types at the seedling stage observed in 2010 and 2012, these materials could be containing other stem rust resistance genes in their background responsible for reduced disease severity. Thus, partially responsive race specific and hypersensitive genes coupled with dominant genes could be in control leading to pseudo resistance given the presence of multiple $P$. graminis f. $\mathrm{sp}$ tritici races found at KARI Njoro. In addition, a co-segregation for both the avirulent and virulent types of the pathogen genotypes based on the gene for gene concept could be in operation (Rubiales and Nicks, 2000).

Short wheat lines with earliness trait have shown high resistance to stem rust in this study. A report by Singh et al. (2008) also highlighted that semi dwarf varieties are associated with reduced stem rust inoculum accumulation. Due to the reduced photosynthetic area for stem rust fungus infection and spread, some wheat lines with high yellow rust disease severity tended to show low stem rust severities (Bancal et al., 2007). This study also observed that stem rust disease directly affects the grain quality leading to shriveling of wheat grains; for example in the check "CACUKE" which had the least TKW value but total susceptibility to the stem rust. Work by Ali et al. (2008) also observed that the susceptible check used in their study showed the least TKW and the least grain yield. Given the ability of the stem rust race Ug99 to adapt and evolve into more virulent pathotypes and even reduce wheat yield, its further spread should be counteracted to ensure sustained high wheat productivity.

\section{CONCLUSIONS AND RECOMMENDATIONS}

Elite sources of resistance to stem rust which combined good agronomic traits identified should urgently be integrated in the wheat breeding programs given the avirulence/virulence nature of the Ug99 race. This could be achieved through the introgression of the identified resistance into the adapted but susceptible Kenyan wheat varieties through intercrosses with other genotypes containing minor genes. This will also help to broaden the genetic diversity of the available wheat germplasm. However, more work to evaluate these elite materials for slow rusting components like latent period, receptivity and uredinium size need to be studied. This could be followed by inheritance studies coupled with marker assisted selection to establish the identity of these genes conditioning the resistance among these lines.

\section{REFERENCES}

Ali S, Shah SJA, Maqbool K (2008). Field-Based Assessment of Partial Resistance to Yellow Rust in Wheat Germplasm. J. Agric. Rural. Dev. 6(1,2):99-106.

Ayliffe M, Singh R, Lagudah E (2008). Durable resistance to wheat stem rust needed. Curr. Opin. Plant. Biol. 11:187-192.

Bancal MO, Robert C, Ney B (2007). Modelling wheat growth and yield losses from late epidemics of foliar diseases using loss of green leaf area per layer and pre anthesis reserves. Annals Bot. 100:777-789.

Bartos P, Sip V, Chrpova J, Vacke J, Stuchlikova E, Blazkova V, Sarova J, Hanzalova A (2002). Achievements and prospects of wheat breeding for disease resistance. Czech J. Genet. Plant. Breed. 38(1):16-28.

Beteselassie N, Fininsa C, Badebo A (2007). Sources of stem rust resistance in Ethiopian tetraploid wheat accessions. Afr. Crop Sci. J. 15(1):51-57.

Burdon JJ (1993). Genetic variation in pathogen populations and its implications for adaptation to host resistance. Durability of disease resistance. Th. Jacobs and J.E. Parlevliet (Eds). Kluwer Academic Publishers, Norwell, MA. pp. 41-56.

Jin $Y$, Singh RP, Ward RW, Wanyera R, Kinyua M, Njau P, Fetch T, Pretorius ZA, Yahyaoui A (2007). Characterization of seedling infection types and adult plant infection responses of monogenic $\mathrm{Sr}$ gene lines to race TTKS of Puccinia graminis f. sp. tr.tici. Plant Dis. 91:1096-1099.

Ooro PA, Bor PK, Amadi DOK (2009). Evaluation of wheat genotypes for improved drought tolerance through increased seedling vigour. Afr. Crop Sci. Conf. Proc. 9:49-53.

Peterson RF, Campbell AB, Hannah AE (1948). A diagrammatic scale for estimating rust intensity on leaves and stems of cereals. Can. J. Res. 26:496-500.

Qamar M (2006). Prediction of level of partial resistance in spring wheat to leaf rust in field through component analysis in greenhouse. Pak. J. Agric. Res. 19(4):46-50.

Roelfs AP, Singh RP, Saari EE (1992). Rust Diseases of Wheat: Concepts and Methods of Disease Management. CIMMIYT, Mexico, DF. ISBN: 968-6127-70-4 p. 81.

Rubiales D, Nicks RE (2000). Combination of mechanism of resistance 
to rust fungi as a strategy to increase durability. CIHEAM -IAMZ. pp.333-339.

Saari EE, Prescott JM (1985). World distribution in relation to economic losses. In: Roelfs, A. P., Bushnell, W.R., editors. The Cereal Rusts. Diseases, Distribution, Epidemiology, and Control. Academic Press, Orlando, FL. 2:259-298.

Semenov MA, Halford NG (2009). Identifying target traits and molecular mechanisms for wheat breeding under a changing climate. J. Exper. Bot. 60(10):2791-2804.

Singh RP, Hodson DP, Huerta-Espino J, Jin Y, Njau P, Wanyera R, Herrera-Foessel SA, Ward RW (2008). Will Stem Rust Destroy the World's Wheat Crop? Adv. Agron. 98:271-309.

Stakman EC, Stewart DM, Loegering WQ (1962). Identification of physiologic races of Puccinia graminis var. tritici. U.S, Agric. Res. Serv. ARS E617:1-53.

Synman JE, Pretorius ZA, Kloppers FJ, Marais GF (2004). Detection of adult plant resistance to Puccinia triticina in a collection of wild triticum species. Genet. Resour. Crop. Evol. 51:591-597.
Tabassum S (2011). Evaluation of advance wheat lines for slow yellow rusting Puccinia striiformis fsp tritici. J. Agric. Sci. 31:239-249.

Vidal J (2009). Airborne fungus Ug99 threatens global wheat harvest. http://www.infiniteunknown.net/2009/03/19/airborne-fungus-ug99threatens-global-wheat-harvest/

Wanyera R, Kinyua MG, Njau P, Kamundia JW, Kilonzo S (2004). Current Status of Stem Rust in Wheat Production in Kenya. 12th Regional Wheat Workshop for Eastern, Central, and Southern Africa. Nakuru, Kenya, 22-26 November pp. 1-243.

Xu SS, Jin Y, Klindworth DL, Wang RRC, Cai X (2009). Evaluation and Characterization of Seedling Resistances to Stem Rust Ug99 Races in Wheat-Alien Species Derivatives. Crop Sci. 49:2167-2175. 